\title{
Política de formação inclusiva: percepção de gestores sobre processo de mudanças em Instituições de Ensino Superior
}

Inclusive education policy: perceptions of managers about the process of changes in Higher Education Institutions

Política de formación inclusiva: percepción de los gestores con relación al proceso de cambios en Instituciones de Enseñanza Superior

\author{
Francilene Jane Rodrigues Pereira', Sérgio Ribeiro dos Santos', Cesar Cavalcanti da Silva' \\ ' Universidade Federal da Paraíba, Centro de Ciências da Saúde, \\ Departamento de Enfermagem Clínica. João Pessoa-PB, Brasil.
}

Submissão: 5/11/2009 Revisão: 7/11/2010 Aprovação: 11/1/2011

\section{RESUMO}

Estudo exploratório descritivo, qualitativo, realizado em Instituições de Ensino Superior que ministram Curso de Enfermagem em João PessoaPB. Objetivou-se compreender a concepção dos gestores sobre a necessidade de mudança organizacional para se adequar à clientela com necessidades especiais. Realizou-se entrevista semiestruturada com gestores das IES e, para interpretação dos dados coletados, utilizou-se o método da análise de discurso, na vertente de Fiorin. Quatro gestores participaram do estudo. Identificou-se preocupação em atender as demandas das políticas de inclusão, inclusive na adequação de espaços físicos e na pedagogia adotada para atender os estudantes. Alguns gestores assumiram pouco preparo pessoal no atendimento à clientela com necessidades especiais, e que as instituições que representavam não dispunham de trabalho logístico eficiente e compatível com as propostas de inclusão preconizadas pela legislação vigente. Conclui-se que o processo de mudanças estruturais e pedagógicas se constrói de maneira lenta e gradual, requerendo atuação de gestores qualificados e comprometidos em executar, civil e legalmente, políticas de inclusão direcionadas a essa clientela.

Descritores: Pessoas com deficiência; Instituições de Ensino Superior; Enfermagem.

\section{ABSTRACT}

This is a qualitative descriptive exploratory study, conducted in Higher Education Institutions (HEI) which offers Nursing course, in Joao Pessoa-PB. The study aimed to understand the concept of managers about the need for organizational changes to attend customers with special needs. Four managers participated in the study. A semi-structured interview with guiding questions was used to collect information and to interpret the data we used the method of discourse analysis based on Fiorin. It was noticed that the managers have a concern to meet the demands of inclusive policies, including the adequacy of physical spaces and the pedagogy adopted to meet the students' needs. However, some of them admitted to have little knowledge on how to deal with students with special needs and also mentioned that the institutions do not have an efficient and logistic work which can meet the current legislation of inclusion. We concluded that the process of structural and pedagogical changes is built in a slow and gradual way and it requires an involvement of qualified managers who are committed to execute the policies of inclusion of customers with special needs in a civil and legal way.

Key words: Disabled persons; Higher Education Institutions; Nursing.

\section{RESUMEN}

Estudio exploratorio descriptivo cualitativo, Ilevado a cabo en Instituciones de Enseño Superior (IES) que ofrecen Curso de Enfermería en João Pessoa-PB. El objetivo del estudio fue comprender la concepción de los dirigentes sobre la necesidad de cambio organizacional para adecuarse a la clientela con necesidades especiales. Cuatro dirigentes participaron en el estudio. Se llevó a cabo una entrevista semiestructurada con los dirigentes, y para interpretar los datos se utilizó el método de análisis de discurso según Fiorin. Se registró preocupación de los dirigentes en atender las demandas de las políticas de inclusión, incluso en la adecuación de los espacios físicos y en la pedagogía adoptada para atender a los estudiantes. Algunos de los dirigentes admitieron poco preparo personal para atender a la clientela con necesidades especiales, como también las instituciones que representaban no disponían de trabajo logístico eficiente y compatible con las propuestas de inclusión preconizadas por la legislación vigente. Se concluye que el proceso de cambios estructurales y pedagógicos en las IES actualmente se construyen despacio y gradualmente, requiriendo actuación de dirigentes cualificados y comprometidos en ejecutar, civil y legalmente, políticas de inclusión dirigidas a esa clientela.

Palabras clave: Personas con discapacidad; Instituciones de Enseñanza Superior; Enfermería. 


\section{INTRODUÇÃO}

A sociedade, ao longo dos anos, considerou a pessoa com necessidades especiais como um ser incapacitado, imutável, não se preocupando em criar serviços para atender suas necessidades individuais. No entanto, quando profissionais começaram um processo de sensibilização e propuseram medidas para o atendimento às necessidades especiais, teve início à construção de conhecimentos e alternativas de atuação na área de educação especial|(1).

A trajetória do ensino superior no Brasil é encontrada em inúmeros estudos que descrevem e analisam sua instalação tardia, os percalços de sua institucionalização, seus projetos e reformas, suas facetas diante dos diferentes momentos políticos, sociais e econômicos vividos no país, sua atual conjuntura, seus conflitos e desafios ${ }^{(2)}$.

A relação do estudante com Necessidades Especiais (NEE) e o ensino superior se constitui um processo interativo em que se devem considerar conjuntamente as suas características e as solicitações, recursos e possibilidades. Esta relação encontra-se, no entanto, condicionada pelo reconhecimento dos direitos da pessoa com NEE. Segundo a UNESCO, há três direitos "educacionais": à educação - a Universidade faz parte do sistema educativo; à igualdade de oportunidades - isto é, o direito de usufruir de oportunidades semelhantes às dos seus pares sem condições de deficiência; à participação social - consubstanciado no direito de usufruir dos equipamentos e condições postos à disposição de toda a comunidade ${ }^{(3-4)}$.

Assim, se os serviços universitários propõem assegurar o direito à educação e à igualdade de oportunidades terão que refletir sobre as condições de acesso capazes de oferecer aos seus ingressantes. Porém, mesmo com a concretização, em 1931, do Estatuto das Universidades Brasileiras, considerado como um dos marcos estruturais da universidade em nosso país, pouco se alterou do caráter excludente e seletivo que vinha caracterizando o Ensino Superior. Ao contrário, o estatuto corrobora para consolidar a hegemonia dos que se pretendiam proprietários do saber, que eram também os proprietários das terras e de todas as riquezas produzidas, e que se valiam do saber para justificar seu poder ${ }^{(5)}$.

Isto demonstra que esse documento representou um instrumento precário e insuficiente para diminuir o quadro de exclusão social e educacional no Brasil. Tão pouco a reforma universitária instituída em 1968, de forma repreensiva e centralizadora, concebeu a universidade pública como um lócus democratizador que primasse pela inclusão educacional(2).

Neste sentido, a inclusão de estudantes com necessidades educacionais especiais no ensino superior requer medidas que facilitem e auxiliem a concretização desse processo, como: formação continuada de professores, produção e adequação de recursos pedagógicos, assessoria psicopedagógica, adaptação de estruturas curriculares, bem como a reflexão de todos os envolvidos no processo educativo. Torna-se necessário a criação de comissões ou núcleos na própria instituição responsáveis pelo desenvolvimento de ações que propiciem a inclusão. Para tal, são requeridas discussões acerca das estruturas físicas e curriculares, a programação dos cursos, das disciplinas que os compõem e dos princípios norteadores das Instituições de Ensino Superior ${ }^{(6)}$.

Em 1996, o Aviso Circular nº 277 MEC/GM sugeriu encaminhamentos para o processo de ingresso de estudantes com necessidades especiais nas IES, sobretudo, pelo concurso vestibular. Chama a atenção para as instituições desenvolverem ações que possibilitem a flexibilização dos serviços educacionais, de infraestrutura, de capacitação de recursos humanos, de modo que atendam uma permanência de qualidade a esses discentes. Nova iniciativa oficial ocorre pela Portaria do MEC $n^{\circ} 1.679 / 1999$, que dispõe sobre os requisitos de acessibilidade a pessoas com deficiências para instruir processos de autorização e de reconhecimento de cursos e de credenciamento de instituições ${ }^{(2)}$.

Ainda no tocante às bases legais, recentemente foi revogada a Portaria $n^{\circ} 1.679 / 1999$ e editada a Portaria $n^{\circ} 3.284 / 2003$ MEC/GM, que dispõe sobre a responsabilidade das universidades públicas, faculdades e centros de ensino em assegurar condições básicas de acesso e permanência aos estudantes com NEE físicas e sensoriais. Determina que na avaliação das condições de oferta de cursos superiores - para autorizá-los, reconhecê-los e renová-los - sejam incluídos requisitos de acessibilidade de pessoas com necessidades especiais ${ }^{(2)}$. Dentre esses requisitos, a referida Portaria determina que a acessibilidade aos estudantes com necessidades físicas compreenderá, no mínimo: eliminação de barreiras arquitetônicas para circulação do estudante, para permitir acesso aos espaços de uso coletivo; reserva de vagas em estacionamentos nas proximidades das unidades de serviço; construção de rampas com corrimãos ou colocação de elevadores, para facilitar a circulação de cadeira de rodas; adaptação de portas e banheiros com espaço suficiente para permitir o acesso de cadeira de rodas; colocação de barras de apoio nas paredes dos banheiros; instalação de lavabos, bebedouros e telefones públicos em altura acessível aos usuários de cadeira de rodas.

Quanto às pessoas com necessidades educativas especiais auditivas ou visuais, a Portaria $n^{\circ} 3.284 / 2003$ esclarece que é compromisso formal das IES, no caso de vir a ser solicitada e até que o estudante conclua o curso: manter sala de apoio equipada com máquina de datilografia e impressora em Braille acoplada ao computador, sistema de síntese de voz, gravador e fotocopiadora que amplie textos, software de ampliação de tela e outros equipamentos para estudantes com NEE visuais. Assim como, oferecer intérprete de língua de sinais, especialmente, durante a realização de testes, flexibilizar a correção das provas escritas, dentre outros itens para atender os alunos com NEE auditivas ${ }^{(2)}$.

Ainda sobre a Portaria $\mathrm{n}^{\circ} 3.284 / 03 \mathrm{MEC} / \mathrm{GM}$, seu artigo $2^{\circ}$ trata da parceira entre a Secretaria de Educação Superior e a Secretaria de Educação Especial, que estabelece os requisitos de acessibilidade tomando-se como referência as normas da Associação Brasileira de Normas Técnicas (ABNT) relacionadas à acessibilidade de pessoas com necessidades especiais, através da preocupação com a edificação, o espaço, o mobiliário e o equipamento urbano. De acordo com essa Portaria, os meios que facilitam a acessibilidade desses discentes precisam ser incorporados por todas as Instituições de Ensino 
Superior, públicas ou privadas, de forma que seja garantida a permanência do acadêmico no curso de graduação ${ }^{(7)}$.

Nota-se que existe preocupação por parte do governo em oferecer e garantir, também no ensino superior, um atendimento educacional para as pessoas com necessidades educacionais especiais. Entretanto, a implementação dessas normas está em uma fase inicial, pois na prática, o processo de inclusão, embora em alguns casos já esteja em andamento, ainda precisa ser efetivado.

Estudos realizados por diversos pesquisadores sobre o acesso e a permanência do universitário com necessidades especiais nas IES do Brasil demonstram que as iniciativas para proporcionar apoio psicopedagógico a esse grupo de estudantes são isoladas e insuficientes para atender à demanda nas universidades ${ }^{(1)}$.

A educação inclusiva é um desafio, é tarefa dos educadores, dos representantes governamentais e de todos os cidadãos, mas para se efetivar uma política inclusiva deve-se ir além da análise e aplicação de documentos legais(8). Acredita-se que, no universo do ensino superior, a prática docente frente a estudantes com necessidades educacionais especiais requer políticas públicas e ações compartilhadas capazes de orientar o educador na formação de sujeitos, valorizando a diversidade em todos os espaços e fazendo valer o verdadeiro sentido da inclusão, como processo que reconhece e respeita diferentes identidades e que aproveita essas diferenças para beneficiar a todos.

Diante dessas incompletudes, é preciso considerar que a universidade pública hoje não pode ser tomada como a única responsável pela inclusão, mas como parte integrante da implementação de políticas públicas que garantam apoio financeiro às ações e iniciativas neste contexto.

Paralelamente a essa situação, tais instituições precisam estar cientes da importância de expor às instâncias governamentais as limitações que enfrentam e de apontar encaminhamentos que devem ser tomados para que haja a garantia de acesso, ingresso e permanência desses estudantes, pois, contam com profissionais das mais diversas áreas do conhecimento, que podem contribuir com ensino, pesquisa e extensão na área das necessidades educacionais especiais ${ }^{(4)}$.

No âmbito administrativo é importante lembrar que se faz necessário aos sistemas de ensino que constituam e façam funcionar um setor responsável pela educação especial, dotado de pessoal, recursos materiais e financeiros que viabilizem e deem sustentação ao processo de construção da educação inclusiva ${ }^{(1)}$.

De igual modo, uma boa organização administrativa e didática que busque contemplar a inclusão desses estudantes deve e pode ser buscada por toda e qualquer IES. Contudo, o respeito às diferenças e à igualdade de oportunidades para todos os indivíduos requer investimentos e ações governamentais nas universidades públicas, pois caso não haja investimento na remoção de barreiras arquitetônicas e educacionais, a efetivação de sua inclusão no ensino superior tornar-se-á mais difícil ${ }^{(4)}$.

No atual contexto educacional a permanência na graduação é mais uma barreira a ser enfrentada pelo estudante com necessidades especiais e o gestor das IES precisam ter sensibilidade e preocupação em adaptar o acesso a estrutura curricular, assim como, preparar os professores e servidores/ funcionários para o atendimento desses indivíduos em sala de aula e demais setores/serviços da instituição.

Portanto, esse estudo surgiu da necessidade de conhecer a reflexão por parte dos gestores sobre a conformidade da grade curricular em suas IES às demandas desses estudantes, inclusive, a adaptação das instituições para oferecer estrutura, tanto física quanto pedagógica, compatível com as necessidades destes para que possam ser acolhidos, terem suas expectativas atendidas e sentirem-se efetivamente sujeitos partícipes do processo educacional(9). O objetivo foi o de compreender a concepção dos gestores sobre a necessidade de mudanças nas Instituições de Ensino Superior para se adequar à clientela com necessidades especiais.

\section{METODOLOGIA}

Trata-se de um estudo exploratório e descritivo com abordagem qualitativa realizado nas Instituições de Ensino Superior que ministram curso de Enfermagem em João Pessoa-PB, Brasil. As IES envolvidas na pesquisa foram a Faculdade de Enfermagem São Vicente de Paula, o Instituto de Educação Superior da Paraíba, a Universidade Federal da Paraíba e o Instituto de Educação da Paraíba. As IES foram nomeadas como IES 1; IES 2; IES 3 e IES 4 não correspondendo, necessariamente, à ordem supracitada.

Os participantes do estudo foram quatro gestores de IES que aceitaram participar da pesquisa. A escolha dos mesmos teve como critérios: apresentarem vínculo com a instituição, estarem presentes no momento da coleta de dados; aceitarem participar da pesquisa após leitura e concordância do Termo de Consentimento Livre e Esclarecido.

A coleta de dados teve início com a aprovação do projeto pelo Comitê de Ética em Pesquisa, através do Parecer nº 0533. Aos participantes foram oferecidas as orientações relacionadas ao estudo, quanto à finalidade da pesquisa e mediante a leitura do Termo de Consentimento Livre e Esclarecido, conforme estabelece a Resolução № 196/96 do Conselho Nacional de Saúde, que regulamenta pesquisa com seres humanos ${ }^{(10)}$.

Para obtenção dos dados foi realizada uma entrevista semiestruturada com os gestores das IES, a fim de compreender a percepção a respeito das mudanças institucionais para adequação aos indivíduos com necessidades especiais. Dessa forma, as entrevistas foram agendadas e gravadas com a permissão do entrevistado. Para interpretação dos dados utilizou-se o método da análise de discurso na vertente Fiorin ${ }^{(11)}$, segundo o qual os depoimentos ocupam uma posição social que materializa, na linguagem, e, veicula, na sociedade, as representações ideológicas dos sujeitos. Deste modo, as falas gravadas dos gestores foram escutadas exaustivamente, transcritas com posterior análise do conteúdo ideológico que estas representavam no contexto histórico e social atual.

\section{RESULTADOS}

Nas entrevistas com os gestores das IES, quatro questões norteadoras foram utilizadas com a finalidade de compreender a concepção desses administradores no tratamento 
ofertado aos Portadores de Necessidades Especais (PNEs) nas instituições de ensino que ministram o curso de enfermagem.

O primeiro questionamento foi: Nesta Instituição, existem políticas de inclusão direcionadas às pessoas com necessidades especiais? Se existem, quais? Se não, por quê? Nesta questão, destacaram-se os seguintes recortes dos depoimentos:

Nós reconhecemos a necessidade de adotar políticas;... Hoje nós já temos algumas rampas, eu acho que construídas de forma inadequada, não são de fácil acesso...; Nós também estamos tentando adequar os banheiros aos PNE, para você vê nossa funcionária recém-chegada, a cadeira dela não passa na porta do banheiro. (IES 1)

Para colocarmos o acesso para deficientes como sanitário, elevador. (IES 2).

Existem: Quota de Contratação de portadores de necessidades especiais; adaptações construtivas nos prédios para facilitar o acesso e circulação; aquisição de elevadores para circulação vertical; banheiros adaptados; estacionamentos reservados; Linguagem Brasileira de Sinais - LIBRAS -incluídas nos currículos. (IES 3)

Sim, mudanças na matriz curricular, com inclusão da disciplina Libras. Adequação dos espaços físicos como biblioteca, salas de aula, banheiros, carteiras diferenciadas, rampas, elevadores, corrimões, oficinas pedagógicas. (IES 4)

Constata-se nos depoimentos dos gestores das instituições participantes que há preocupação com algumas modificações no sentido de atender as demandas dos PNEs. Na IES 1, as políticas de inclusão apenas são postas em prática coerentemente quando existem professores e estudantes na instituição com alguma necessidade especial. Na IES 2, quando se refere a mudanças, são citadas soluções na estrutura física, porém os PNEs não necessitam de melhorias das condições apenas nesse aspecto. Nas duas outras instituições, as mudanças em diversas amplitudes foram lembradas pelos gestores dessas empresas, revelando conhecimento das necessidades nos seus diversos níveis de atendimento às pessoas com necessidades especiais.

A segunda questão abordou: Como as mudanças estruturais têm ocorrido ou estão sendo planejadas pela instituição para tal inclusão?

Rampas, adequação dos banheiros, os principais eu digo são essas; acesso ao ônibus (...), então é uma preocupação também. (IES 1)

Já estão sendo executadas, como eu disse antes: nós temos elevador para esse acesso, nós temos as rampas, os sanitários, tudo em ordem. (IES 2)

A parte física dos prédios antigos é adaptada aos padrões atuais de atendimento aos portadores de necessidades especiais e os novos já são construídos para atender a essas necessidades. (IES 3
Fazendo reuniões de dirigentes, professores e funcionários, adquirindo equipamentos e construindo áreas físicas, estacionamentos. (IES 4)

As mudanças estruturais perfazem um papel de extrema importância no trato com os PNEs nas diversas instituições. Nesta perspectiva, percebe-se a significação desse fator no ideário dos gestores, pois todas as instituições apontadas no estudo estão se adequando no aprimoramento dos espaços físicos para atendimento de tais necessidades visando à adequação a legislação vigente e cumulativamente abrangendo número ainda maior de indivíduos ao ensino superior. Mudanças esses representadas pela construção e/ou reforma de áreas antes impróprias para o livre acesso, ampliando a facilidade na circulação dos PNE.

$\mathrm{O}$ terceiro questionamento aos gestores foi: $\mathrm{O}$ corpo docente é pedagogicamente preparado para atender as demandas de aprendizado dessa clientela? Se sim, como? Se não, por quê?

Mas, eu acho que, no geral, os professores não são, assim, capacitados, não foram orientados e talvez não atentem para essa questão da necessidade especial. (IES 1)

\section{O corpo docente é preparado. (IES 2)}

Sim. O corpo docente é orientado a atender a portadores de deficiências especiais, respeitando as suas limitações e adotando práticas diferenciadas que os ajudem a ter um desempenho normal nas atividades do curso. (IES 3)

Não, porém, estão sendo treinados a cada trimestre. (IES 4)

Outro componente de especial importância, porém de visualização mais discreta no corpo da instituição, é a metodologia do ensino aplicada na formação profissional, com o propósito de promover a transferência, manutenção e absorção do conhecimento pelos estudantes desenvolvidos pelos professores àqueles com necessidades especiais.

O que pode ser interpretado nos depoimentos é a diferenciação de opiniões por parte dos gestores. O gestor da IES 1, justifica-se da ausência de orientação pela instituição e ainda por não condizer com a realidade cotidiana da presença de estudantes com necessidades especiais. Além disso, estes passam desapercebidos pelos professores que não sentem, a priori, a necessidade de aprimoramento pedagógico.

Em poucas palavras, o gestor da IES 2 relata que o seu corpo docente é pedagogicamente preparado, porém não entra em detalhes. Na IES 3, o gestor relata a orientação dedicada pela instituição a seus professores com a finalidade de adotar práticas coniventes com a clientela. Enquanto que, o gestor da IES 4, apesar de afirmar que seu corpo docente não estar preparado, revela que realiza um treinamento trimestral na instituição dedicado aos professores. Intui-se, assim, um certo grau de exigência desses gestores que apesar de orientarem e treinarem seus funcionários quatro vezes ao ano, ainda não atingiram as expectativas dos idealizadores de tal projeto. 
A última questão formulada aos gestores foi: Como avalia a atual situação do ensino dessa instituição no preparo de profissionais com necessidades especiais?

Eu acho que é ainda incipiente (...) não temos ainda trabalhado as pessoas e nem as condutas para a visão das necessidades desse tipo de pessoa, por isso eu digo, que há um despreparo, não há conscientização, eu tenho visto que só quando ocorre necessidade é que vislumbramos aquilo e tentamos solucionar. (IES 1)

No nosso ensino, a instituição já está bem preparada, nós temos hoje o ensino integrado que é totalmente diferente, trabalhamos com a qualidade propriamente dita. (IES 2)

No Curso de Enfermagem como nos demais desta IES, o ensino busca atender necessidades específicas do estudante, de modo a que haja uma equalização de competência e conteúdo entre eles e aqueles portadores de necessidades especiais. (IES 3)

Precisa investir mais, inclusive ampliando o elenco de necessidades temporárias e/ou permanentes. (IES 4)

A qualidade do ensino nas Instituições de Ensino Superior deve ser direcionada no intuito de acolher sujeitos diferenciados por gênero, cultura, religião, entre outras, porque é parte de sua filosofia essa união de sujeitos individualizados de características peculiares e pensamentos únicos. E, para tal, devem preparar-se para o acolhimento dessa diversidade.

O gestor da IES 1 revela incipiência no preparo da instituição para atender pessoas com necessidades especiais, tendo em vista que, nem os recursos humanos, nem os materiais foram adequados a essa finalidade. Já o gestor da IES 2, afirma que a instituição está preparada, porém a justificativa não satisfaz a temática em questão, visto que o sistema integrado de ensino é apenas um método de mudanças nas grades curriculares dos cursos, com o objetivo de separar os conteúdos em módulos semelhantes, independente da clientela sem ou com necessidades especiais. Na IES 3, o gestor relata a busca do atendimento das necessidades específicas de cada estudantes e deste com os demais. O gestor da IES 4 demonstra preocupação em ampliar suas dimensões no ensino-aprendizado aos PNEs.

\section{DISCUSSÃO}

A partir dos depoimentos dos gestores compreende-se que os maiores avanços no atendimento das necessidades dos PNEs têm ocorrido nas instituições privadas de ensino, isso acontece em decorrência da natureza institucional. Esses avanços têm possibilitado o atendimento de um mercado pouso visualizado nas instituições públicas, em discordância com o que estabelece a Constituição Federal do Brasil, no artigo 205: “Educação é um direito de todos e um dever do estado"(12).

Há de se reconhecer que as políticas direcionadas para a busca da inclusão dos PNEs em Instituições de Ensino Superior devam alvejar transformações que vislubrem as possibilidades de mudanças não puramente estruturais ou arquitetônica, com alterações nos locais de acesso, construção de rampas, elevadores, corrimões, banheiros públicos e/ou outras adaptações capazes de facilitar o trânsito desses indivíduos na espacialidade dos centros de ensino. Por outro lado, há necessidade de alterações metodológicas no acolhimento, ensino e avaliação da aprendizagem que somadas ao conjunto de políticas institucionais possibilitem, também, a permanência, o bom desempenho e a qualidade do ensino-aprendizado.

No aspecto relacionado ao planejamento das mudanças estruturais, pode-se destacar o gestor da IES 4 que, além de relatar a adequação do espaço físico, realiza o planejamento das modificações em conjunto com os demais atuantes no processo de trabalho da instituição, ativando a participação de todos os envolvidos nas estratégias de mudança buscando informações e ideias que diferindo dos desejos e vivência dos gestores, contribuem satisfatoriamente para uma visão ampliada das várias interfaces do cuidado com os PNEs.

É perceptível na organização, quando existe essa troca de informações e pensamentos, o funcionário se sente participante ativo das ações da instituição. Todos se beneficiam, pois autores e co-autores se desdobram num ideário comum visando à notoriedade do serviço, assim como, a integração dos profissionais nas tomada de decisões.

Pode-se inferir pelo depoimento dos gestores que apenas a IES 1 admite o despreparo do seu corpo docente. Nessa instituição, em função de seu caráter de gratuidade do ensino, a exigência no atendimento das normas são lentificadas, fato a ser explicado pela falta de imposição e pressão social, inexistentes. Além do mais, nesses serviços a hierarquia burocrática caminha vagarosamente pela dependência da aprovação de um grande número de pessoas e recursos, por vezes, em falta ou ainda mal utilizados.

Observa-se ainda, que os serviços educacionais, independente se público ou privado, apesar dos respaldos legais que amparam os direitos dos portadores de necessidades especiais, ainda não se mostram completamente estruturados para acolher esses indivíduos. A integração constatada em documentos e discursos políticos ainda não tem sido prioridade nos projetos direcionados para educação. O gestor da IES 1, por entender não ser único responsável pelas políticas, declara que há insuficiência em atender as necessidades dos PNEs. Já o gestor da IES 2 busca justificativas pouco coerentes para justificar a estrutura curricular adotada em relação à temática.

Por outro lado, os gestores da IES 3 e IES 4, na tentativa de manter seu mercado plenamente funcionando com serviços prestados a todos que frequentam a instituição, revelam-se preocupados com a manutenção e aprimoramento de ações direcionadas aos PNEs, pois a atração dos indivíduos para essas instituições de ensino, pelo investimento aplicado exige alta qualidade.

Apesar das lacunas existentes na atenção aos PNEs, não se permite deixar de reconhecer que nas últimas décadas, avanços existiram, quando antes se buscava a inserção desses indivíduos no ensino superior, hoje se anseia pela efetivação do acesso e permanência. Algumas conquistas já foram alcançadas, mas torna-se urgente uma ação articulada entre 
pessoas com necessidades educativas especiais, IES, governo e sociedade para a construção de uma sociedade igualitária e democrática.

A relevância social das necessidades especiais extrapola a esfera da saúde e atinge a sociedade como um todo, visto que essas pessoas possuem as mesmas necessidades de outras além das peculiares à sua condição ${ }^{(13)}$. Cabe acrescentar que a degradação da qualidade de vida desses sujeitos aumenta ainda mais quando além da necessidade especial, a pobreza também se faz presente e está atrelada a fatores como a (des) educação, o desemprego, a violência e as dificuldades de acesso a serviços de saúde e de aprendizado(14).

\section{CONSIDERAÇÕES FINAIS}

Considerando a importância da temática da inclusão, ainda incipientemente discutida, para não dizer quase escassa entre as publicações em saúde, este estudo objetivou compreender a concepção dos gestores de IES em enfermagem da cidade de João Pessoa-PB sobre a necessidade de mudanças a fim de adequarem-se à clientela com necessidades especiais.

Para execução do mesmo, a disponibilização dos gestores em participarem da pesquisa foi de fundamental importância, apesar da dificuldade de acesso a alguns deles. Enriquecedor também foi o método de análise escolhido para interpretação dos dados - Vertente Fiorin - pois possibilitou a integração ideológica dos depoimentos dos sujeitos aos fatos históricos e sociais da atualidade. Esta análise revelou que as IES demonstram preocupação em atender as demandas das políticas de inclusão, tanto no que se refere à estrutura física quanto pedagógica. Porém, algumas delas ainda assumem caráter de pouco preparo e até afirmam tal posição no atendimento aos estudantes com necessidades educativas especiais que ingressam em sua organização. Ocorre, nas IES pesquisadas, um processo de mudanças construído de maneira lenta e gradual requerendo atuação de gestores qualificados e comprometidos em executar cívil e legalmente políticas de inclusão.

Nesta perspectiva, as contribuições oriundas dos resultados obtidos neste estudo revelam haver um processo em franco andamento em direção a redemocratização do ensino superior em enfermagem na Paraíba que abre as portas da educação para pessoas com necessidades especiais, possibilitando, mesmo que ainda de forma discreta, a qualificação profissional desses indivíduos.

Este estudo contribuiu, também, para ampliação do leque de possibilidades em pesquisa na enfermagem, haja vista que publicações sobre essa temática encontram-se prioritariamente na área da educação, em contrapartida, escassas na área da saúde.

\section{REFERÊNCIAS}

1. Pacheco RV, Costa FAT. O processo de inclusão de acadêmicos com necessidades educacionais especiais na Universidade Federal de Santa Maria. Rev Educ Especial [Internet] 2005;(27). [citado 5 set 2008]. Disponível em: http://coralx.ufsm.br/revce/ceesp/2006/01/a12.htm.

2. Moreira L C. In(ex)clusão na universidade: o aluno com necessidades educacionais especiais em questão. Rev Educ Especial [Internet] 2005;(25). [citado 5 set 2008]. Disponível em: http://coralx.ufsm.br/revce/ceesp/2005/01/a3.htm.

3. Unesco "Declaração de Salamanca e Enquadramento da ação na área das Necessidades Educativas Especiais", IIE, Lisboa, 1994.

4. Rodrigues D. A inclusão na Universidade: limites e possibilidades da construção de uma Universidade Inclusiva. Rev Educ ação Especial [Internet] 2004;(23). [citado 5 set 2008]. Disponível em: http://coralx.ufsm.br/revce/ceesp/2004/01/ a1.htm.

5. Garcia RL. O papel social da universidade e sua repercussão na formação de professores. Movimento: Revista da Faculdade de Educação da Universidade Federal Fluminense 2000;(2):67-79.

6. Eidelwein MP. Pedagogia universitária voltada à formação de professores na temática da inclusão. Rev Educ Especial [Internet] 2005; (26). [Citado 15 dez 2008]. Disponível em: http://coralx.ufsm.br/revce/ceesp/2005/02/r9.htm.

7. Ministério da Educação (BR). Portaria $n^{\circ} 3.284$, de 7 de novembro de 2003. Acessibilidade a pessoas portadoras de deficiências para instruir processos de autorização e de reconhecimento de cursos e de credenciamento de instituições. Brasília(DF): Ministério da Educação; 2003.

8. Castanho DM, Freitas SN. Inclusão e prática docente no ensino superior. Rev Educ Especial [Internet] 2005;(27). [citado 2 maio 2009]. Disponível em: http://coralx.ufsm. br/revce/ceesp/2006/01/a6.htm

9. Andrade MSA, Pacheco ML, Farias SSP, Pessoas com deficiência rumo ao processo de inclusão na Educação Superior. Revista Digital de Pesquisa CONQUER da Faculdade São Francisco de Barreiras [Internet] 2006;(1). [citado 13 abr 2009]. Disponível em: http://www.fasb.edu.br/revista/ index.php/conquer/article/view/27/9.

10. Ministério da Saúde (BR). Conselho Nacional de Saúde. Diretrizes e normas regulamentadoras de pesquisa envolvendo seres humanos. Brasília(DF): Ministério da Saúde; 1997.

11. Fiorin JL. Elementos de análise do discurso. São Paulo: Contexto; 2005.

12. Constituição 1988 (BR). Constituição da República Federativa do Brasil. Brasília (DF): Senado Federal; 1988.

13. Pagliuca LMF, Regis CG, França ISX. Análise da comunicação entre cego e estudante de Enfermagem. Rev Bras Enferm [Internet], Brasília 2008;61(3):296-301. [Citado 9 jan 2009]. Disponível em: http://www.scielo.br/pdf/reben/ v61n3/a03v61n3.pdf.

14. França ISX, Pagliuca LMF. Utilitarismo, pobreza e desenvolvimento dos portadores de deficiência. Rev. Latino-Am. Enfermagem [Internet] 2007;(15). [Citado 10 jun 2009]. Disponível em: http://www.scielo.br/pdf/rlae/v15nspe/pt_21.pdf 